\title{
The Effects of Pre Modified Input, Interactionally Modified Input, and Modified Output on EFL Learners' Comprehension of New Vocabularies
}

\author{
Zinat Maleki (Corresponding author) \\ MA in TEFL, Tabriz Branch, Islamic Azad University, Tabriz, Iran \\ E-mail: maleki.z77@gmail.com
}

AbdolReza Pazhakh

English Language Department, Dezful Branch, Islamic Azad University, Dezful, Iran

E-mail:pazhakh@gmail.com

Received: April 7, 2012

Accepted: April 28, 2012

Published: May 15, 2012

doi:10.5430/ijhe.v1n1p128

URL: http://dx.doi.org/10.5430/ijhe.v1n1p128

\begin{abstract}
The present study was an attempt to investigate the effects of premodified input, interactionally modified input and modified output on 80 EFL learners' comprehension of new words. The subjects were randomly assigned into four groups of pre modified input, interactionally modified input, modified output and unmodified (control) groups. Each group included 20 students. The participants in the experimental and control groups were taught under different conditions. In each session a matrix picture of a place and its furniture and equipments was given to the participants and they were trained to find the right position of each item. Statistically, analyses were conducted through a one-way ANOVA and Tukey test. The findings of the study revealed that the participants in interactionally modified input group achieved the highest comprehension scores than their peers in other three groups $(\mathrm{P}<0.05)$. In addition, modified output group outperformed both premodified input and control groups. However, there was no significant difference between premodified input and control groups and both of them obtained the lowest comprehension scores.
\end{abstract}

Keywords: Pre modified input, Interactionally modified input, Modified output, Comprehension of new words

\section{Introduction}

A prime importance has been given to the role of input comprehension in the second language acquisition (SLA) research and theory, and most second language acquisition researchers accepted the idea that exposure to the target language input is necessary for the SLA. "All types of data from a target language that the learners are exposed to and from which they learn called "input"” (Anani Sarab \& Karimi, 2008, p.183). The input received by second language learners (L2) is often modified in order to make it more comprehensible and therefore to improve the process of SLA.

Comprehensible input is a hypothesis that first proposed by Krashen (1981). He claimed that L2 learners can acquire language by understanding messages that are slightly above their current English language level. The studies on comprehensible input have concerned with how to make the input comprehensible to the learners or non-native speakers (NNSs) through studying the native speakers' (NSs) speech or teacher talks in different classrooms and contexts.

\subsection{Three Potential Sources of Comprehensible Input}

1) Modified input

Current L2 researches have tried to identify the factors that make the input comprehensible to the learners. Input comprehension was considered in different kinds of linguistic environments. The first type is termed as modified input. In fact in this approach, native speakers (Ns) modify their input to facilitate non-native speakers' (NNSs) comprehension. This modification can be maintained in different forms, like repetitions, paraphrase of words or sentences, and reduction of sentence length and complexity, among others. According to Ziglari (2008), it has been assumed that language acquisition can be fostered by the modified input in the environment; i.e., when the native speakers as proficient speakers adjust their language to the level of low-level learners (foreigners) to make it more comprehensible. So, this 
kind of linguistic environment is characterized by the input which has been modified or simplified before the learner sees or hears it.

2) Interactionally Modified Input

The second potential source of comprehensible input for L2 learning is interactionally modified input which is characterized by the opportunities for native speaker- non native speaker (NS- NNS) interactions in which both of them have to modify and reconstruct the interaction in order to arrive at a mutual understanding. In fact, it was Long (1980) that made an important distinction between modified input and interaction. This interaction has special features which help the participants negotiate meaning. He has asserted that NNSs and NSs employ some strategies in their social discourses, including some aspects of conversations such as comprehension checks, clarification requests, topic shifts and self and other repetitions and expansions. He has claimed that speakers modify interactions using these strategies in order to avoid or solve conversation problems and repair discourse when misunderstanding sequences arise. When L2 learners face communicative problems and they have the opportunity to negotiate on solutions to them, they are able to learn language.

\section{3) Modified Output}

The next part of the study deals with modified output. The theoretical basis on the importance of output was first put forth by Swain's Comprehensible Output Hypothesis (1985). She argued that while comprehensible input and the emphasis on interactional negotiation is essential, the role of interactional exchanges in second language acquisition "may have much to do with comprehensible output as it has to do with comprehensible input" (p.236).

Accordingly, modified output, second language learners try to reformulation their own utterances, and this type of modification has been attracting researchers' interest as an important component of learner interactions, and as a manifestation of interlanguage development and psycholinguistic processing. This hypothesis has been used as a theoretical framework to investigate the relationship between modified output and L2 learning. It has been assumed that the input which is comprehensible and interaction which has been modified can facilitate the process of second language acquisition.

\subsection{Research Questions}

1) Does premodified input have any effects on EFL learners' comprehension of new words?

2) Does interactionally modified input have any effects on EFL learners' comprehension of new words?

3) Does modified output have any effects on EFL learners' comprehension of new words?

a. Krashen's Input Hypothesis

Krashen (1980), in his Input Hypothesis claimed that in order for L2 acquisition to take place, a learner must be exposed to and understand the comprehensible input that contains language structures beyond his or her current stage of competence which he calls it " $i+1$ " (Krashen, 1982, p.21). ' $i$ ' refers to the current knowledge of a learner and ' 1 ' to the next level. In other words, for moving from stage ' $i$ ' to ' $i+1$ ', the learner must understand the input containing $i+1$, with one new piece of input.

The most important characteristic is comprehensibility. According to Krashen (1982, p.63), "It amounts to the claim that when the acquirer does not understand the message, there will be no acquisition". It means that incomprehensible input can not be useful in SLA.

How input becomes comprehensible to language learners? Krashen offered two answers to this question: 1) using the context by the learner and 2) presenting simplified input by the teacher.

\section{b. Long's Interaction Hypothesis}

In fact, Long's Interaction Hypothesis is an extension of the Input Hypothesis. Long (1983) has argued that not only simplification and contextual clues lead to comprehensible input, but also modification of the interactional structure of conversation. These modifications occur when a communication problem arises and the interactants negotiate to seek solutions to it. Like the Input Hypothesis, Long's Interaction hypothesis had more focused on input rather than output as the source of acquisition. The difference between these two hypotheses is that unlike the Input Hypothesis, Interactional Hypothesis focused on the learner's output.

c. Swain's output Hypothesis

Swain (1985) has argued for the insufficiency of comprehensible input. She has believed that though comprehensible input may play an important role in SLA, it is not sufficient and has mentioned that understanding and acquiring are not 
the same. In her output Hypothesis, she emphasized the role of outcome in SLA and asserted the insufficiency of comprehensible input as well as she argued that SLA takes place when input becomes intake. Learners improve their language proficiency by pushing them to produce output or by using language exposed to them in meaningful ways. Although Swain did not claim that comprehensible output is the most important factor for all or even most language acquisition, she argued that under some conditions, comprehensible output can facilitate second language learning in some ways.

\section{Empirical Background to the Study}

Gass (1997, P: 1) believed that "the concept of input is perhaps the single most important concept of SLA. It is trivial to point out that no individual can learn a second language (L2) without input of some sort". As it was noted before, there are three different potential sources of comprehensible input namely premodified input, interactionally modified input and modified output and many researchers have tried to identify what makes input comprehensible to the learners.

\subsection{Premodified Input and L2 Learning}

According to Park (2002), a learner modifies or simplifies his/her input in some ways, before he/she sees or hears it. This modification or simplification can be done by repetition, paraphrase of words or sentences and reduction of sentence length and complexity.

The studies applied within this framework focused on describing modifications those different speakers- a mother i.e., motherese, a native speaker e.g., foreigner talk, or a teacher e.g., teacher talk, make when addressing a child or a second language learner. There are two kinds of premodified input: simplification and elaboration.

Simplified input can be in the form of less complex syntax and limited vocabulary. In simplified input, in order to make the original input comprehensible for the learners, all potential unfamiliar and unknown words are omitted from the text.

Elaboration refers to "Features such as slower speech, cleverer articulation, and emphatic stress, paraphrases, synonyms, restatements, rhetorical signaling devices, self-repetition, and suppliance of optimal syntactic signals serve neither to simplify nor to make complex the surface form . . . rather they are clarifications of meaning only, opportunities for the listener/ reader to better decode the communication" (Parker and Chaudron, 1987, p. 110).

Parker and Chaudron (1987) have compared the effects of different types of modifications on L2 learners' comprehension of academic discourse. The participants were 43 undergraduate and graduate ESL learners who read two different passages: simplified and elaborated. The researchers found a greater correlation between comprehension of an elaborated passage and independent measures of reading than between comprehension of a simplified passage and independent measures of reading.

Urano (2002) has studied the effects of lexical simplification and elaboration on sentence comprehension and incidental vocabulary acquisition. The participants in the study were six low intermediate learners of English. Four of them were Japanese and the other two were Korean. S/He confirmed that lexical elaboration had more effects than lexical simplification in terms of both L2 reading comprehension and vocabulary acquisition.

In addition, Keshavarz and Mobarra (2003) have compared the effects of simplification and elaboration on reading comprehension of 140 Iranian EFL learners. They required subjects to read 5 reading passages that included three forms: unmodified, simplified and elaborated. According to the results the participants did nearly the same in elaborated and simplified reading passages

More recently, Shirinzarii (2011) has investigated the effects of text modification (simplification and elaboration), on Iranian EFL learners' incidental vocabulary acquisition. She conducted her experiment on 90 Iranian university students. The results indicated that those students who read the elaborated texts had the lowest scores, while the scores of the readers of the baseline texts and simplified texts were the highest with a slight superiority of the baseline texts group.

\subsection{Interactionally Modified Input and L2 Learning}

There are a number of researches that investigated the effects of interactional adjustments on comprehension and vocabulary acquisition.

Most studies have investigated the role of input and output in conversational interactions and have mainly focused on NS interactional moves as well learners' response to NS interactional moves in NS-NNS interaction. A considerable number of studies, however, have also investigated NNS-NNS interactions, examining whether learners are able to provide some useful linguistic feedback to other learners. (E.g., Long, 1982; Pica et al, 1987; Ellis, Tanaka \& Yamazaki, 1994; Loschky, 1994; Mackey, Gass \& McDonough, 1999). Most of these studies are related to the difficulties that 
learners and their interlocutors have in understanding each other's message and their attempts to make themselves understood to each other.

Pica, Young and Doughty (1987) have compared pre modified input with the input modifications produced during negotiated interactions. They compared how a) baseline input, b) premodified and c) interactionally modified input affect adult learners' comprehension. They predicted that the nonnative speaker's (NNS) comprehension would be lower in the premodified input directions than in the unmodified input directions with interaction allowed.

The results of their study showed that comprehension on the part of the NNSs was lower in the premodified directions than in the unmodified input with interaction. Their findings supported the idea that interaction and repetition through interaction increased comprehension.

Ellis et al. (1994) have investigated, in their two studies, the effects of modified interactions on comprehension and vocabulary acquisition. They chose 79 third-year students at a public high school for the first study, and 127 first-year high school students for the second one. The researchers noticed five hypotheses out of which numbers 2 and 3 dealt with negotiation, comprehension and acquisition.

Hypothesis 2 claimed that learners receiving input through interaction would achieve higher levels of L2 comprehension than those exposed to other types of input. The outcomes of their study supported the claim. It means that the students who were given the chance to negotiate their problems in comprehension were more successful in carrying out the directions.

Hypothesis 3 predicted that learners with the chance of interaction would learn and retain more L2 words than those learners who received other kinds of input. This turned out to be the case, as the learners who negotiated the input achieved higher vocabulary acquisition scores in the immediate posttest and also, they maintained this advantage over time.

Boroghani, (2002) has investigated the effect of modified oral input (premodified and interactionally modified input) on the acquisition of word meanings. The subjects were 62 third year high school students. The first group received premodified oral input and the second group interactionally modified oral input and finally she found that the interactionally modified group acquired more word meanings and the results showed that interactional modification of oral input significantly influenced the subjects' performance.

Baleghizadeh and Borzabadi (2007) also found that interactionally modified input condition improves reading comprehension more than linguistic modifications do, thus confirming the findings of the previous studies i.e., Pica et al. (1987) and Ellis et al. (1994).

\subsection{Modified Output and L2 Learning}

Similarly, there were several empirical studies of modified output which investigated the process by which learners modify their ungrammatical output in response to their interlocutors' feedback. Some of them investigated whether modified output through negotiation work results in restructuring of a learner's interlanguge system.

Pica (1988) has conducted a study in order to discover how learners negotiate comprehensible output. The aim of the study was to find out how nonnative speakers make their output comprehensible when native speakers indicate that they have difficulty understanding.

However, the results did not confirm her hypothesis. Some variables can explain the unexpected result, one of them is the methodological approach adopted in the study. In her follow-up study which controlled the methodological limitations of the previous study, Pica and her colleagues revealed that learners were more desired to modify their output by making it more grammatical in response to requests for clarification.

Ellis and He (1999) have investigated the differential effects of modified Input, interactionally modified input and modified output on L2 comprehension and acquisition. The learners in modified output group had the opportunity to produce and modify their own output to other learners. Although, it was the modified output condition that achieved significantly higher level of vocabulary acquisition than the other two conditions but it was difficult to contrive conditions that distinguished modified input and modified output since "modified output does not occur in vacuum- it occurs as a response to input and to the opportunity to interact" (p.299).

Ogino (2008, cited in Xiaohui, 2010), has explored whether modified output played a facilitative role in L2 learning. The results did not clearly revealed whether or not learners were conscious of avoiding the use of the same non-target-like forms that they previously modified. In fact it indicated the limited role of the modified output in L2 development. 
Masayoshi, (2008) has explored the impact of modified output on L2 learning, by means of an experimental pre-test and delayed post design. The data were 28 undergraduate students. The results of the study revealed that production of modified output in respond to clarification request may facilitate the progress of interlanguage development towards target like use even when its immediate impact on grammatical accuracy may not be observed.

However, the findings did not clearly demonstrate whether or not production of modified output might sensitize learners to avoid the using same non-target like form that they have previously modified. This reveals the limited role of production of modified output in L2 learning, and suggests that the modified output learners' feedback may be necessary to maximize the effect of modified output in facilitating L2 learning.

\section{Method}

The aim of this study was to investigate the effects of pre modified input, interactionally modified input, and modified output on Iranian EFL learners' comprehension of new vocabularies.

\subsection{Participants}

The participants in this study were 80 Iranian freshmen, majoring in English teaching at Andimeshk Islamic Azad University, 40 of them were female and the other 40 were male. All the participants were learning English as foreign language (EFL) with an age range of 19 to 27 years old.

In order to select a homogenous sample, the researcher administered a proficiency PET test (2004) to 140 participants as the population of the study. On the basis of the results related to the subjects' performance in the test, 80 students whose scores ranged from 70 to 80 out of 100 , were selected and randomly assigned into four groups: Premodified input group $(n=20)$, interactionally modified input group $(n=20)$, modified output group $(n=20)$ and control group $(n=20)$. They were taught some vocabularies under different conditions.

\subsection{Instrumentation}

The instruments for the purpose of this study were a preliminary PET (2004) test, a vocabulary test as a pre test and another vocabulary test as the post test and also, the study material was Oxford picture dictionary (1998).

At first, a proficiency PET (2004) was administered to the population participating in the study a week before the study in order to elicit a homogeneous sample from the population under study. The subjects, whose scores ranged between 70 to 80 out of 100 , were selected to participate in the experiment as the sample of the study. After administrations the PET test, however, 60 students whose scores were below 70 or above 80 were removed from the study.

Then a vocabulary test was administered as a pre test during the same week before the study. This test included those vocabularies that would be taught during the course. A list of different words was given to the subjects and they were asked to read all of the vocabularies and check all the words that they were familiar with and write down the Persian meaning of each word. Based on the results of the test, the vocabularies which were known by the subjects were eliminated from the course and those which were unknown for all of them were selected for the course.

After the end of one semester, a posttest was designed to measure the subjects' proficiency level to recognize the meanings of words. The test consisted of a list of 55 vocabularies taught during the course and the subjects were asked to write the Persian meaning of each item in front of it. This post test was the same for all four mentioned groups.

\subsection{Procedure}

The study lasted for about a semester (12 sessions). In each session which lasted about 50 minutes a matrix picture of a place (kitchen, apartment, store ....) and its furniture and equipments (e.g., knife, cupboards, shelves, sofa ....) was given to the students. These pictures and their related words were taken from Oxford picture dictionary (1998). Then based on different methods, the subjects were trained and asked to find the right position of each item which explained by the teacher.

\subsubsection{The pre modified input treatment}

Under this condition, the subjects listened to their teacher's descriptions/definitions of new vocabulary items. The teacher explained the meaning of those words in simplified language. A matrix picture of a place and a series of its furniture and equipments related to that specific picture were given to the subjects and they listened to their teacher gave instructions to find the right place of each item. The teacher described or defined the items at a slow rate, providing simplified input that is normally characteristic of foreigner talk.

Ten items of each picture were taught by the teacher each of which had one point. After hearing some directions and explanations by teacher and without any interaction with teacher or their peers, the students were asked to find each 
word in the matrix picture. Neither were they allowed to ask any questions nor did they have the right to have any suggestions.

\subsubsection{The interactionally modified input treatment}

Under this condition, the matrix pictures of different places with their furniture and equipments were given to the subjects. Then they interacted with their teacher and tried to find the correct picture of any item that explained by her. The teacher wrote some directions for requesting clarification on the board, and then read them at a normal speed. The students had the opportunity to interact with her and use her clarification in order to understand the meaning of the sentences.

\subsubsection{The modified output treatment}

First, the teacher read the words and explained them one by one at a normal speed and the students wrote each word next to the pictures, then they worked in pairs and interacted with their classmate orally.

Then, the task was performed in groups. Students negotiated with other groups and in this way they modified their own output. So, students' pair work and group work are the main characteristics of this class.

\subsubsection{The control group treatment}

Here, the teacher translated the words and then she asked some students to read the words orally. The students were asked to memorize the Persian meaning of each word. There was not so much interaction between teacher and students and the teacher was the real author in the class. She had enough time to review the words for the second time. In fact, here the words were instructed in old and traditional methods, without any modification, pair/group works or interactions.

Each treatment would include 10 items with one point assigned to each item. In modified input group and control group the time was enough for review and repetition, but in interactionally modified input and modified output groups there was no time to review or repetition.

\section{Data Analysis}

Using the statistical package for social science version 16 the data necessary were analyzed. One sample t-test was used to analyze the results of PET test and then the One-Way ANOVA was used to compare the groups. At the end, the Tukey HSD was used to analyze the scores of all four groups.

In order to ensure that the groups were homogenous in PET (2004) test, a one-sample test was used. This test was administered to determine whether there were significant differences in their language proficiency level or not. Tables (4.1 and 4.2) (see appendix A) indicate that there were no significant differences in the performances of the subjects.

The results of preliminary test analysis among all participants in the study signified that there was no significance difference between them regarding their language proficiency. Table 4.1 shows that the mean score of all participants was 75.28 .

Regarding the mean scores of all four groups, it was found out that the mean score of interactionally modified input group was higher than other three groups (16.90), suggesting that the interactionally modified input group acted better than other groups on the post test. As Table 4.3 shows interactionally modified input group achieved the mean score 16.90 out of 20 that is the highest mean score.

The results of analyzing the post test scores indicated a significant difference between four groups. In other word, each group performed differently after the instruction and the interactionally modified input group outperformed the other three groups. As Table 4.3 (see appendix A) shows $(\mathrm{F}=22.50$ ); and $\mathrm{P}<0.5$, the assumption of equivalence of the mean scores was rejected. In addition, modified output group acted better than both the premodified input and the control groups. Furthermore, a Tukey HSD test was subsequently applied to further examine the direction of the differences among all groups.

Table 4.4 (see appendix A) shows the results of comparing the mean scores of different groups with each other. Positive scores show that the first group acted better than the second one and negative scores reveal that the first group acted worse than the first one. So, the mean difference between interactionally modified input group and all other three groups were positive, that is to say, there was a statistically significant effect for interactionally modified input on total scores. $(\mathrm{MD}=1.900 ; \mathrm{MD}=4.05 ; \mathrm{MD}=4.70)$. This suggests that interactionally modified input had a facilitative role in $\mathrm{EFL}$ learners' comprehension of new words. In addition, the difference is significant $(\mathrm{P}<.05)$. In addition, the mean score of the participants in the modified output group $(\mathrm{M}=-1.90 ; \mathrm{M}=2.15 ; \mathrm{M}=2.80)$ is significantly higher than the mean score 
of participants in the modified input group $(\mathrm{M}=-4.050 ; \mathrm{M}=-2.15 ; \mathrm{M}=0.65)$ which again reveals that modified output can facilitate EFL learners' comprehension of new words.

\subsection{Discussion}

The findings of the present study showed that although learners in all four groups obtained some reasonable comprehension scores, the participants in both interactionally modified input and modified output groups significantly outperformed their peers in the premodified input and control groups on the post test. In addition, the participants in interactionally modified input group that had opportunity to negotiate with their teacher, achieved the highest level of comprehension. It means that interactionally modified input condition worked better than the other three groups. The participants in premodified input group obtained the mean score of 12.20 , while the mean score of interactionally modified input group was 16.90, and the one in modified output group was 15.00 and the control (unmodified) group obtained the mean of 12.85. As it was mentioned in pervious parts, the difference was significant $(\mathrm{P}<.05)$, so it can be constructed that significant differences existed in the performance of the interactionally modified input and modified output groups but there was not any significant difference between the premodified and the control (unmodified) group.

Question 1. Does premodified input have any effects on EFL learners' comprehension of new words?

The first research question asked about the relative effects of premodified input on EFL learners' comprehension of new words.

As it was expected, the scores on premodified input group were lower than those on interactionally modified input group and modified out put group. However, the findings of the study answered the first question of the research that premodified input has positive but low effect on EFL learners' comprehension of new words. So, the first research null hypothesis was rejected. The difference in scores between the premodified input group and the control group was small and there was not any statistical significance difference between the mean scores of these two groups; in fact, both of them obtained the lowest scores.

Many researchers have studied about simplification and elaboration and their effects on L2 learning. Some of these studies such as Parker and Chaudron (1987), Keshavarz and Mobarra (2003), have investigated the relative effects of simplified and elaborated texts on comprehension. Some of them (e.g., Shirinzarii. (2011) have showed greater comprehension for simplified and elaborated versions as opposed to the unmodified texts, but there was no significant difference between simplified and elaborated texts. In contrast, the others (e.g., Parker and Chaudron (1987), Urano, (2002), ) have claimed that elaboration can have a significant effect on reading/vocabulary comprehension rather than simplification. However, the present study did not considered the effects of simplification and elaboration on L2 learning process and the aim of this study was to have a comparison between all types of modifications that is premodified input, interactionally modified input and modified output.

Question 2. Does interactionally modified input have any effects on EFL learners' comprehension of new words?

The second question of the research was related to the relative effects of interactionally modified input on EFL learners' comprehension of new words. Based on the obtained results, there are some evidences that interactionally modified input had better effect on Iranian EEL learners' comprehension of new words than the other three groups. So the second question was answered affirmative and also, the second research null hypothesis was rejected.

This is in line with the findings of similar studies such as Pica et al., (1987); Ellis et al., (1994); Boroghani, (2002). All of these researchers asserted that interactionally modified input had the most effective role in comprehension, recognition or production of new words than the premodified input. However, the focus of the present study was on comprehension. It is worth to mention that in some studies like Ellis (1994) the participants in interctionally modified input group had more time to do their tasks, while in the present study the allocated time was same for all four groups.

In contrast to the previous studies such as Van den Branden (1997); Ellis and He, (1999), Masayoshi (2008), this study failed to indicate any advantage for modified output than interactionally modified input.

Question 3. Does modified output have any effects on EFL learners' comprehension of new words?

The third research question asked about the relative effects of modified output on Iranian EFL learners' comprehension of new words and according to the obtained results, modified output has positive effect on EFL learners' comprehension of new words and the third research null hypothesis was rejected.

The mean score of the participants in the modified output group was higher than both pre modified and control group, but it was lower than the interactionally modified input group. Therefore, it lied in between. It was found that the modified output has lower effect on EFL learners' comprehension of new words than the interactionally modified input. 
Based on different theories and with regards to previous researches in this area, the present study was formed and revealed that the interactionally modified input had the highest and the best effect on EFL learners' comprehension of new words. The findings of the study were in line with Krashen's Input Hypothesis and Long's Interaction Hypothesis and suggested that input modification and interaction can promote the process of L2 learning. The participants in modified output group could not obtain the highest scores such as their peers in interactionally modified input group. This can be explained by considering two types of interaction in these two groups. In interactionally modified input group the interaction was between teacher as the more proficient speaker and student as the less proficient speaker. So, the teacher provided useful and necessary information and clues for the student and guided him/her to understand the correct meaning of the words. While, in modified output group almost all students were at the same level of proficiency and they did not have the chance to use the clarifications of their teacher. However, this point should be explained that in this study all groups had the same amount of time to complete their tasks and all of the four groups had similar tasks in different conditions.

The main finding of the study, however, lies in the significantly higher mean score of the interactionally modified input group compared with other three groups, claiming that interactionally modified input has a more facilitative role in Iranian EFL learners' comprehension of new words.

\section{Conclusion}

Based on the findings it might be concluded that:

1) Interactionally modified input group acted better than modified output group. As it was mentioned before, three was not any significant difference between premodified input group and control group and both of them obtained the lowest mean scores. However, the mean score of modified output group was higher than the mean score of premodified input group and it reveals that modified output group has more positive effect on comprehension of new words than premodified input group.

2) The study also claimed that teacher-student exchange which occurred in interactionally modified input condition, worked better than the student-student interaction in modified output condition. So, the group that had the opportunity to interact with their teacher worked better than ones without any interaction and those that had interaction with their own peers.

3) We can conclude that we should stress the importance of teacher-student interaction in language learning and teaching which teacher directs and guides the students to have the best understanding through his/her clarifications.

\section{References}

Anani Sarab, M. \& Karimi, M. (2008). The Impact of Simplified and Interactionally Modified Input on Reading Comprehension of Iranian EFL Learners. Shahid Beheshti University. Retrieved November, 3, 2010 from http://www.SID.ir

Baleghizadeh, S. \& Borzabadi, D. (2007). The impact of two types of input modification on EFL reading comprehension. Linguistic versus interaction. TELL, 1(3), 71-94.

Boroghani, T. (2002). Modified oral input and acquisition of word meanings. Unpublished MA thesis.

Ellis, R. (1985). Understanding second language acquisition. Iran University of Science and Technology. Retrieved November, 3, 2010 from http://www.SID.ir

Ellis, R., \& He. X., (1999). The roles of modified input and output in the incidental acquisition of word meanings. Retrieved November, 6, 2010 from http:// www. SID.ir.

Ellis, R., Tanaka ,Y., \& Yamazaki, A.(1994). Classroom interaction, comprehension and the acquisition of word meanings. Language Learning, 44, 449- 491. http://dx.doi.org/10.1111/j.1467-1770.1994.tb01114.x

Gass, S. (1997). Input, interaction, and the second language learner. Mahwah, NJ: Lawrence Erlbaum Associates.

Keshavarz, M. \& Mobarra, M. (2003). The effects of simplification and elaboration on reading comprehension of Iranian EFL learners. Retrieved October, 24, 2010 from http://www.Sid.ir

Krashen, S.D. (1980). The input hypothesis: Issues and implications. In E. Park (2002). Retrieved October, 15, 2010 from http://www.journal.tc-library.org. 
Krashen, S. (1981). Second Language Acquisition and Language Learning. Oxford: Pergamon. In: Park, E. (2002). On three potential sources of comprehensible input for second language acquisition. Retrieved October, 15, 2010 from http://www.journal.tc-library.org.

Krashen, S. (1982). Principles and practice in second language acquisition. Englewood Cliffs, N.J.: Prentice Hall.

Loschky, L. (1994). Comprehensible input and second language acquisition: What is relationship? Studies in second Language Acquisition, 16,303-323. http://dx.doi.org/10.1017/S0272263100013103

Long, M. (1980). Input, interaction, and second language acquisition. In Park, E. (2002). Retrieved October, 15, 2010 from http://www.journal.tc-library.org.

Long, M. (1982). Native speaker/non-native speaker conversation in the second language classroom. In M. Long \& C. Richards (eds.), Methodology in TESOL: A book of reading, 339-354. New York, U.S.: Newbury House.

Long, M. (1983). Native/non-native speaker conversation and the negotiation of comprehensible input. Applied Linguistics, 4,126-141. http://dx.doi.org/10.1093/applin/4.2.126

Mackey, A., Gass, A., \& McDonough, K. (1999). How do learners perceive interactional feedback? Studies in Second Language Acquisition, 22,471-47. http://dx.doi.org/10.1017/S0272263100004022

Masayoshi,O.(2008).Modified output in response to clarification requests and second language. Retrieved September, 20, 2010 from http:// www.SID.ir.

Ogino, M. (2008). Modified output in response to clarification requests and second language learning. (Doctorial dissertation). Available from ProQuest Dissertations and Theses database.

Park, E. (2002). On three potential sources of comprehensible input for second language acquisition. Retrieved October, 15, 2010 from http://www.journal.tc-library.org.

Parker, K. \& Chaudron, C. (1987). The effects of linguistic simplifications and elaborative modifications on L2 comprehension. University of Hawaii working papers in ESL, 6, 107- 133. Retrieved October, 15, 2010 from http://www.sagepub.com

Pica, T. (1988). Negotiated interaction as an aid to learner output. Language Learning, 37, 471-493.

Richards, J.C. \& Schmidt, R. (2002). Longman Dictionary of Language Teaching \& Applied Linguistics. Pearson Education Limited.

Shapiro, N., \& Adelson, J., (1998). The Oxford Picture Dictionary. Oxford University Press.

Shirinzarii, M. (2011). Two types of text modification and incidental vocabulary acquisition: Simplification vs. Elaboration. Retrieved February, 27, 2011 from http://www.Iranian EFL Journal.com

Swain, M. (1985). Communicative competence: Some roles of comprehensible input and comprehensible output in its development. In S.Gass \& C. Maddan (Eds.), Input in second language learning acquisition (pp.2350252). Rowley, MA: Newbury House.

Urano, K. (2002). Effects of simplification and elaboration on L2 comprehension and acquisition. Retrieved June, 27, 2011 from http://www.Urano-ken.com

Xiaohu,H.(2010). An Empirical Study on the Effects of Comprehensible Input on Incidental English Vocabulary Recognition. Retrieved November, 15, 2011 from http://www.celea.org.cn

Ziglari, L. (2008). The role of Interaction in L2 Acquisition: An Emergencies Perspective. Retrieved July, 6, 2011 from http:// www.eurojournals.com/ejsr.htm

Appendix A: Tables

Table 4.1 Descriptive Statistics of the Preliminary Test

\begin{tabular}{|l|l|l|l|l|}
\hline \multicolumn{5}{|c|}{ One-Sample Statistics } \\
\hline & N & Mean & Std. Deviation & Std. Error Mean \\
\hline $\mathrm{X}$ & 80 & 75.28 & 3.052 & .341 \\
\hline
\end{tabular}


Table 4.2 One-Sample t-test of the Preliminary Test

\begin{tabular}{|c|c|c|c|c|c|c|}
\hline \multicolumn{7}{|c|}{ One-Sample Test } \\
\hline & \multicolumn{6}{|c|}{ Test Value $=75$} \\
\hline & \multirow[t]{2}{*}{$\mathrm{t}$} & \multirow[t]{2}{*}{ df } & \multirow[t]{2}{*}{ Sig. (2-tailed) } & \multirow[t]{2}{*}{ Mean Difference } & \multicolumn{2}{|c|}{$95 \%$ Confidence Interval of the Difference } \\
\hline & & & & & Lower & Upper \\
\hline $\mathrm{x}$ & .806 & 79 & .423 & .275 & -.40 & .95 \\
\hline
\end{tabular}

Table 4.3 Descriptive Statistics of the Post test (All Groups) on the Post test

\begin{tabular}{|c|c|c|c|c|}
\hline \multicolumn{5}{|l|}{ Case Summaries } \\
\hline \multicolumn{2}{|l|}{ SCORE } & & & \\
\hline METHOD & $\mathrm{N}$ & Mean & Std. Deviation & Variance \\
\hline 1. Interactionally modified input & 20 & 16.90 & 2.074 & 4.30 \\
\hline 2. Modified output & 20 & 15.00 & 1.89 & 3.57 \\
\hline 3. Control group & 20 & 12.85 & 2.23 & 4.97 \\
\hline 4. pre modified input & 20 & 12.20 & 1.85 & 3.43 \\
\hline Total & 80 & 14.23 & 2.72 & 7.39 \\
\hline
\end{tabular}

Table 4.4 Analyses of the Post Test scores (All groups)

\begin{tabular}{|l|l|l|l|l|l|}
\hline SCORE & Sum of Squares & df & Mean Square & F & Sig. \\
\hline Between Groups & 274.93 & 3 & 91.64 & 22.50 & .000 \\
\hline Within Groups & 309.55 & 76 & 4.07 & & \\
\hline Total & 584.48 & 79 & & & \\
\hline
\end{tabular}

Table 4.4 Tukey HSD on the Post Test

\begin{tabular}{|c|c|c|c|c|c|c|c|c|}
\hline \multicolumn{9}{|c|}{ Multiple Comparisons } \\
\hline \multicolumn{9}{|l|}{ SCORE } \\
\hline \multicolumn{9}{|c|}{ Tukey HSD } \\
\hline \multirow{2}{*}{\multicolumn{2}{|c|}{ (I) METHOD }} & \multirow{2}{*}{\multicolumn{2}{|c|}{ (J) METHOD }} & \multirow{2}{*}{$\begin{array}{l}\text { Mean Difference } \\
(\mathrm{I}-\mathrm{J})\end{array}$} & \multirow[b]{2}{*}{ Std. Error } & \multirow[b]{2}{*}{ Sig. } & \multicolumn{2}{|c|}{$95 \%$ Confidence Interval } \\
\hline & & & & & & & Lower Bound & Upper Bound \\
\hline \multirow{12}{*}{$\begin{array}{l}\text { dimensi } \\
\text { on2 }\end{array}$} & \multirow{3}{*}{$\begin{array}{l}\text { 1.Interactionally } \\
\text { modified input } \\
\text { group }\end{array}$} & \multirow{3}{*}{ dimension 3} & 2 & $1.90^{8}$ & 63 & .020 & .22 & 3.57 \\
\hline & & & 3 & $4.05^{8}$ & 638 & .000 & 2.37 & 5.72 \\
\hline & & & 4 & $4.70^{8}$ & .63 & .000 & 3.02 & 6.37 \\
\hline & \multirow{3}{*}{$\begin{array}{l}\text { 2. Modified out } \\
\text { group }\end{array}$} & \multirow{3}{*}{ dimension 3} & 1 & $-1.90^{8}$ & 63 & .020 & -3.57 & -.22 \\
\hline & & & 3 & $2.15^{8}$ & 63 & .006 & 47 & 3.82 \\
\hline & & & 4 & $2.80^{8}$ & 63 & .000 & 1.12 & 4.47 \\
\hline & \multirow[t]{3}{*}{ 3. Control group } & \multirow{3}{*}{ dimension 3} & 1 & $-4.05^{8}$ & 63 & .000 & -5.72 & -2.37 \\
\hline & & & 2 & $-2.15^{8}$ & 63 & .006 & -3.82 & -.47 \\
\hline & & & 4 & 65 & 63 & .739 & -1.02 & 2.32 \\
\hline & \multirow{3}{*}{$\begin{array}{l}\text { 4. Premodified } \\
\text { input group }\end{array}$} & \multirow{3}{*}{ dimension 3} & 1 & $-4.70^{8}$ & 63 & .000 & -6.37 & -3.02 \\
\hline & & & 2 & $-2.80^{8}$ & 63 & .000 & -4.47 & -1.12 \\
\hline & & & 3 & -.650 & 638 & .739 & -2.32 & 1.02 \\
\hline
\end{tabular}

*. The mean difference is significant at the $\mathrm{P}<.05$ level. 